\title{
Frequency response analysis technique for induction motor short circuit faults detection
}

\author{
A. A. Alawady ${ }^{1}$, M. F. M. Yousof ${ }^{2}$, N. Azis ${ }^{3}$, M. A. Talib ${ }^{4}$ \\ ${ }^{1,2}$ Faculty of Electrical and Electronic Engineering, Universiti Tun Hussein Onn Malaysia, Malaysia \\ ${ }^{3}$ Faculty of Engineering, Universiti Putra Malaysia, UPM Serdang, Malaysia \\ ${ }^{4}$ Tenaga Nasional Berhad Research, Kawasan Institusi Penyelidikan, Malaysia \\ ${ }^{1}$ College of Technical Engineering, The Islamic University, Najaf, Iraq
}

\begin{tabular}{l} 
Article Info \\
\hline Article history: \\
Received Apr 17, 2020 \\
Revised Jul 22, 2020 \\
Accepted Aug 3, 2020 \\
\hline
\end{tabular}

Keywords:

Frequency response analysis Induction motor NCEPRI algorithm Short circuit fault Stator winding fault

\begin{abstract}
The paper presents the description for diagnostic methods of induction motor's stator windings fault. The presented methods use Frequency Response Analysis (FRA) technique for detection of Winding Faults in Induction Motor. This method is previously reliable method for faults diagnosis and detection in many parts of transformers including transformer windings. In this paper, this method was used for motor windings faults detection. This paper presents the FRA response interpretation on internal short circuit (SC) fault at stator winding on three cases studies of different three-phase induction motors (TPIM), were analysed according to two status: healthy induction motor at normal winding status and same motor with windings shorted of main windings. A conclusion of this paper provides the interpretation of and validation the FRA response due to internal SC fault case by using NCEPRI algorithm, which is considered as one of certified statistical indicators. The proposed method in this paper had a useful result for detect and diagnosis of stator windings faults of TPIM. The applications of developed method can be used to detece the other machines types faults.
\end{abstract}

This is an open access article under the CC BY-SA license.

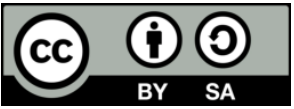

\section{Corresponding Author:}

\author{
A. A. Alawady, \\ Department of Electrical and Electronic Engineering, \\ Universiti Tun Hussein Onn Malaysia (UTHM), \\ 86400, Parit Raja, Batu Pahat, Johor, Malatsia. \\ Email: ahmed.a.alawady@gmail.com
}

\section{INTRODUCTION}

The induction motor is a singly excited machine. The electrical power electro-motive-force (EMF) was supplied to the winding of stator part only. Both of voltage (V) and current (I) pass through stator part windings is induced in the rotor part of machine. So, this machine was defined as induction motor (IM). The rotor part of IM is unconnected with any outside power supply (electrical source). This type of AC motor is designed to operate on single phase AC supply or on three phase AC supply and accordingly that the induction motors called single phase IM (SPIM) and 3-phase induction motor (TPIM) [1, 2]. Almost 95\% of the motors used in industries are TPIM due to their features than SPIM and other types of machines [3, 4, 5]. The different faults which are usually happen in TPIM are electrical faults such us, stator and rotor faults. Motor stator windings fault or break-down is one of the main reasons of TPIM failure [6]. The knowledge of motor faults and appropriate study are so fundamental and important. Therefore, we able to be ready to go for condition monitoring (CM) of IM and suitable diagnosis of the issue, which is reduce the cost of expensive maintenance. The main reasons of winding faults are always related to insulation failure. They are commonly parlance known as phase-to-ground turns fault (PGTF) or phase-to-phase turns fault (PPTF). As believed in 
some times that the winding faults are begin as weakly turn-to-turn faults (TTF) but it is undetected. Subsequently, those weakly faults will evolve and reach culminate to become major faults [7]. These TTF, PGTF and PPTF are inter dependable faults and sometime one of these faults leads to others. Any failure in TPIM leads to losses in production or stops, high maintenance cost and sometime in major faults need to replace the TPIM and pay money for that. Therefore, to avoid any catastrophic failure it may cause unwanted downtime of production, faults should be detected and diagnosis in incipient level [8]. The electric power research institute (EPRI) presented a statistical survey in 1985 and found that $41 \%$ of motor failure is due to bearing faults, $37 \%$ is due to stator faults, $10 \%$ is due to rotor faults while the other failures were $12 \%$ [9-11].

The strategy for variables diagnostic that effect on diagnosis of internal windings short-circuit (SC) faults in TPIM was presented in $[12,13]$ through proven that the internal short-circuit (SC) turns can be detect by using motor current signature analysis (MCSA) technique. Moreover, in $[14,15]$ the MCSA-based techniques used for detecting of the interturn stator winding faults in IM was discussed. In [16], the authors were analyzed the axial flux component of the machine using a large coil wound concentrically around the shaft of the machine for turn-to-turn faults detection. $[17,18]$ have shown by using both experimentation and modeling of IM that these windings faults lead to in asymmetry in winding impedance of induction motor that effects on IM causing to draw unbalanced signature for phase currents. This is the results negativesequence currents (NSC). However, the NSC can also be caused by many effects such as: machine saturation, voltage unbalance, etc. To reduce slip variation and temperature effects on the NSC measurement, the author in article [19] using a power decomposition technique (PDT) to reduce negative-sequence reactance (NSR) and harmonic effects. Articles [20] and [21] suggested a way for machine faults detection through the change in positive-sequence-current (PSC) monitoring by using the multiple reference frame theory.

The industrial defects cause in a structural asymmetry in IM is analyzed using SFRA [22]. Therefore, the SFRA technique is also able to diagnostic and detect the defects in structural asymmetry accurately in the TPIM. Which is also by this technique, we able to detect many faults in TPIM windings. This method is previously reliable method for faults diagnosis and detection in many parts of transformers including transformer windings as presented in previous papers [23, 24]. In [25, 26] and [27], the authors described the methods for detection and diagnostic stator windings fault in IM windings. The authors proposed a method by using acoustic signals to analyses three cases on one case study of induction motor winding: (a) Healthy motor winding, (b) Motor winding shorted circuit in auxiliary part and (c) Motor winding shorted circuit in both of main and auxiliary parts.

This paper investigates the effect of faulty short-circuit winding on a three-phase induction motor (TPIM) using FRA technique. The TPIMs were chosen in this study have a different power rating. The three cases studies of TPIM were analysed in this paper according to two status: healthy induction motor at normal winding status and same motor with windings shorted of main winding. This study verify the findings of TPIM stator winding frequency response (FR) in faulty short-circuit winding condition by using a model of mathematical or statistical indicator, the North China Electric Power Research Institute (NCEPRI) algorithm in [28] has been used for analysing the responses in this paper. The importance of this study lies with shows the ability of FRA to detect the faulty winding in TPIM.

\section{INDUCTION MOTOR USED IN EXPERIMENTAL WORK}

In this study, there are three units of three-phase induction motor with different specifications were used, 1HP TPIM, 2HP TPIM and 3HP TPIM. The first, second and third experimental TPIM are connected as Wye (Y) winding configuration. Details for these three tested units are shown in Table 1. This paper focus on the Wye (Y) connection between 3-phases $\mathrm{U}, \mathrm{V}$ and $\mathrm{W}$ which is widely used for TPIM. The windings short circuit (SC) fault usually occurs to TPIM. Thus, the current in the stator winding will be creased. Due to this, the stator windings experience the thermal stress and insulation failure. This is one of the main factors that effects on stator winding fault in TPIM.

Table 1. Specifications of three phase induction motor units

\begin{tabular}{cccc}
\hline Motor & Motor 1 Specifications & Motor 2 Specification & Motor 3 Specification \\
\hline Manufacturer & JILANG & JILANG & JILANG \\
Model & 110RK-3DS & Y90S-2 & Y90L-2 \\
Phases & 3-Ph induction motor & 3-Ph induction motor & 3-Ph induction motor \\
Power & $0.75 \mathrm{KW} / 1 \mathrm{HP}$ & $1.5 \mathrm{KW} / 2 \mathrm{HP}$ & $2.2 \mathrm{KW} / 3 \mathrm{HP}$ \\
Rated Voltage & $415 \mathrm{~V} / 50 \mathrm{~Hz}$ & $415 \mathrm{~V} / 50 \mathrm{~Hz}$ & $415 \mathrm{~V} / 50 \mathrm{~Hz}$ \\
RPM & $1500 \mathrm{rpm}$ & $2840 \mathrm{rpm}$ & $2840 \mathrm{rpm}$ \\
\hline
\end{tabular}




\section{METHODOLOGY FOR FAULT AND MEASUREMENT}

In this study, three units of TPIM were used to create SC fault in the windings. The purpose of making this artificial fault is to study the differences in windings response that may be occur due to this fault. To diagnose and detect (SC) fault in TPIM windings, FRA measurement on TPIM was performed before (at normal windings condition) and after the fault has created. Windings frequency responses monitoring are analyzed and interpreted after the comparison of responses. In this paper, FRA response measurements are performed on phases $\mathrm{U}, \mathrm{V}$ and $\mathrm{W}$. In this study, the SC fault was applied only on phase $\mathrm{U}$ in the laboratory. Figure 1 shows the creation stages for SC fault on one case of TPIM.

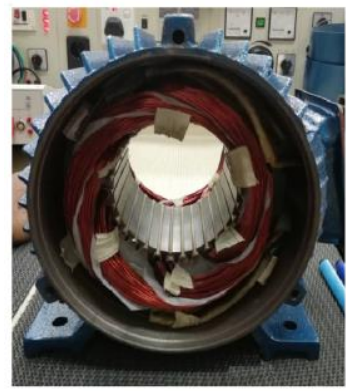

(a)

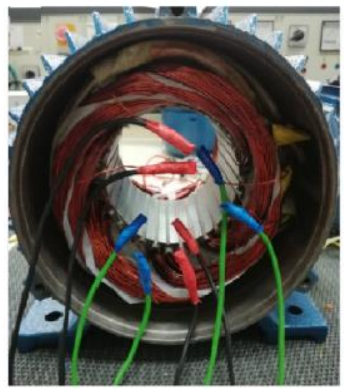

(b)

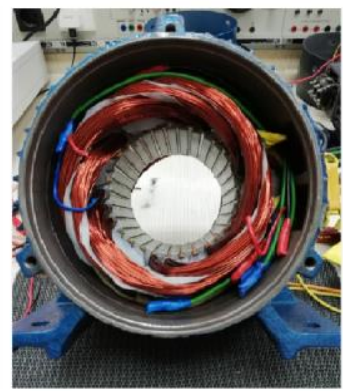

(c)

Figure 1. SC faults procedures on TPIM, (a) Normal winding,

(b) Removing some conductors to create the fault, (c) Completed winding with SC fault.

To perform the FRA measurements of 3-phase induction motor windings connection between FRA equipment, motor terminals and computer are shown in Figure 2. Measurement procedure was determined based on winding connection configuration which is Wye (Y). For Wye connected windings, the FRA response can be measured between two phase terminals $(\mathrm{U}-\mathrm{V}, \mathrm{V}-\mathrm{W}$, and $\mathrm{W}-\mathrm{U})$ or between phase to neutral terminals (U-N, V-N, and $\mathrm{W}-\mathrm{N})$. In this study, assuming that the neutral point $(\mathrm{N})$ is hidden. The FRA responses were measured between phase terminals (U-V, V-W, and $\mathrm{W}-\mathrm{U})$. The practical measurements were made on three units of TPIM as listed in Table 1.

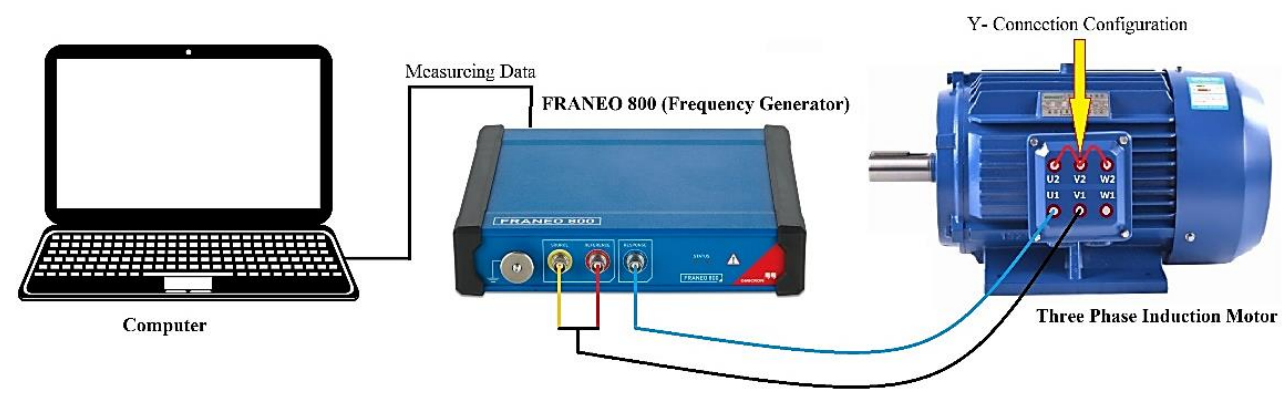

Figure 2. Example of test cable connection to measured FRA for motor windings

\section{FRA RESULTS AND ANALYSIS}

The results of created SC faults FRA practically in the laboratory are presented here in this section. The FRA response on TPIM stator windings of three units tested are shown in Figures 3, 4 and 5. Two responses were measured for each two phases, one during normal status (Healthy winding condition) and the second at SC windings fault in the TPIM windings. The frequency response (FR) curve are divided into four regions. These regions are located at a definite frequency area, which it must be definite according to the response wave-shape. The FR curve will be different from machine to other. Generally, the FR is depending on the IM power rating, windings type, windings configuration, structure of the machine. 


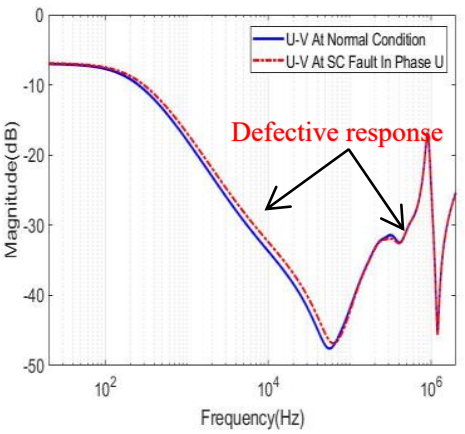

(a)

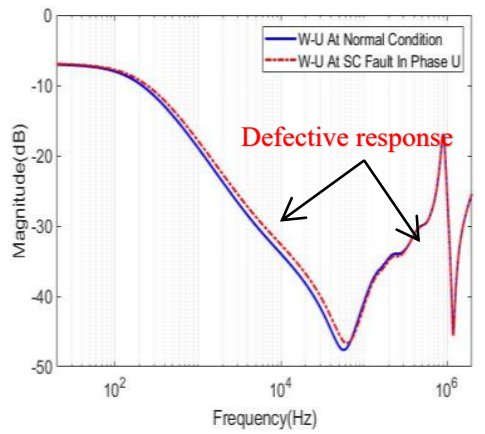

(b)

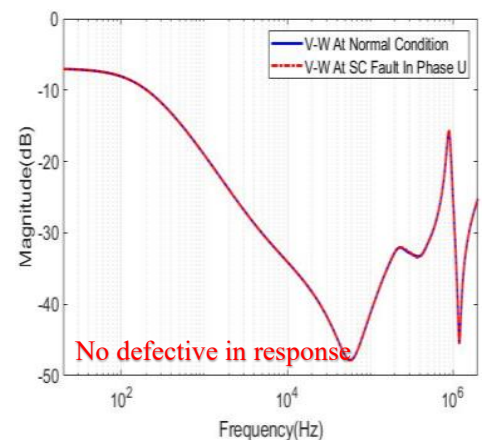

(c)

Figure 3. FRA measurement for phases of 1HP TPIM at normal condition and SC fault in phase U.

(a) FRA for phase U-V, (b) FRA for phase W-U and (c) FRA for phase V-W.

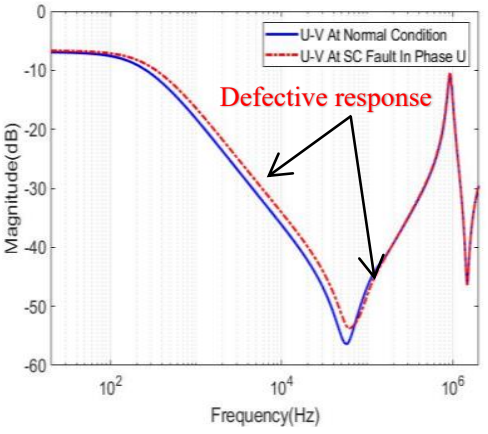

(a)

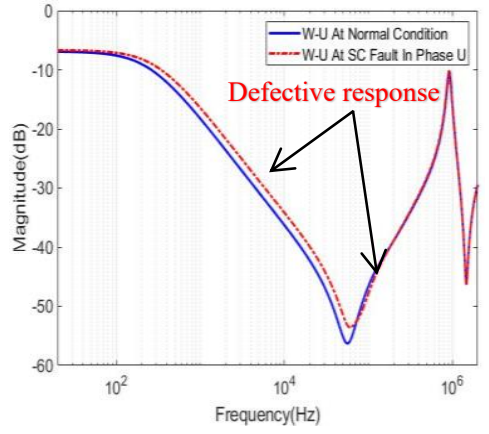

(b)

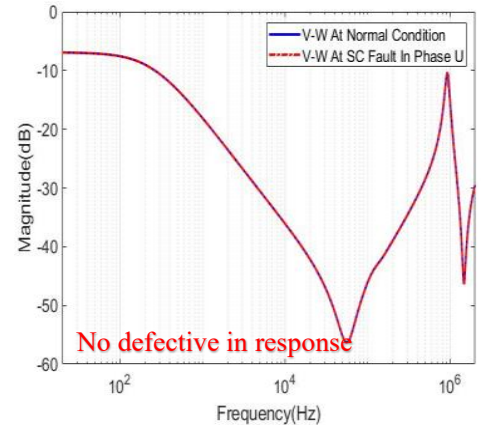

(c)

Figure 4. FRA Measurement for phases of 2HP TPIM at normal condition and SC fault in phase U (a) FRA for phase U-V, (b) FRA for phase W-U and (c) FRA for phase V-W.

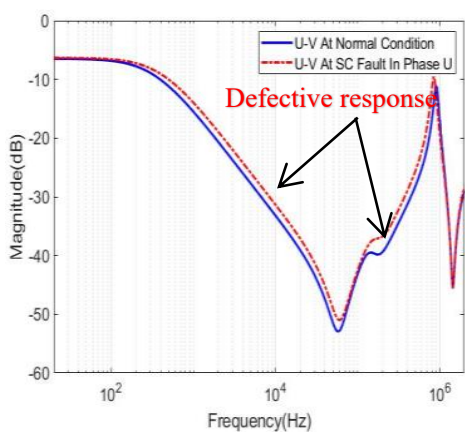

(a)

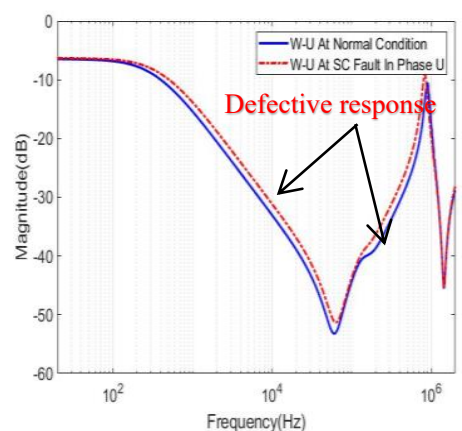

(b)

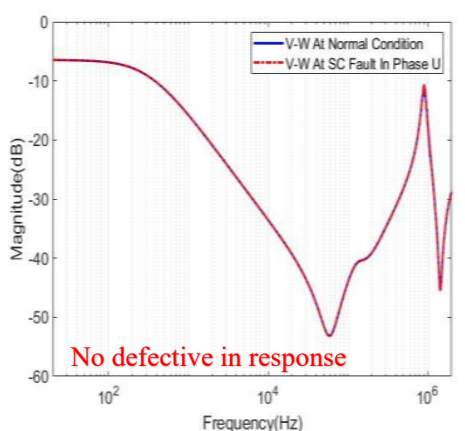

(c)

Figure 5. FRA Measurement for phases of 3HP TPIM at normal condition and SC fault in phase U (a) FRA for phase U-V, (b) FRA for phase W-U and (c) FRA for phase V-W.

The internal short-circuit SC fault in TPIM stator windings, generally leads to a reduction of the electrical windings' length of the coil (a smaller number of turns than the normal condition). Thus, the total resistance of the coils that make up the phase will decrease. Thus, the flux in the coils will reduce. This is one of the main signs of the SC fault in the stator winding for TPIM. Therefore, during this fault, the turns that removed from phase $\mathrm{U}$ to create the $\mathrm{SC}$ fault will lead to reduced magnetizing inductance of Phase $\mathrm{U}$. Thus, causes an increase the magnitude of the response, this led to happening a defective in response as shown in 
Figure 3 (a)-(b), Figure 4 (a)-(b) and Figure 5 (a)-(b). In caused of the SC fault in the same phase windings as the FRA response performed, the amount of shift between the reference measurements and measurements at fault condition are affected because of magnetizing inductance limitation in the stator part of TPIM.

The comparison of frequency responses (FR) in case of normal condition and SC winding fault was shown in Figure 3, Figure 4 and Figure 5, the response shows the cases of effect according to the connections of measurements conducted, which are the FRA response will measure between phases as (U-V, V-W, W-U). the FRA that measured between phase $\mathrm{U}$ to phase $\mathrm{V}$ at SC fault condition shows a defective response was happened as also in FRA measured for phase $\mathrm{W}$ to phase $\mathrm{U}$ for all three units of TPIM as shown in Figure 3 (a)-(b), Figure 4 (a)-(b) and Figure 5 (a)-(b). The frequency response curve for phase $\mathrm{V}$ to phase $\mathrm{W}$ at SC fault case in comparison with the reference response of normal winding condition, does not give any shifting in the response as shown in Figure 3 (c), Figure 4 (c) and Figure 5 (c). This is due to lack of any direct impact on this phases $\mathrm{V}$ and $\mathrm{W}$ unless the measurement passes through the faulty phase $\mathrm{U}$.

\section{FRA RESULTS ANALYSIS USING NCEPRI ALGORITHM}

To do the interpretation and validation for the frequency response (FR), a model of mathematical or statistical indicator be use. Usually, this indicator be a method to distinguish the similarities and differences between frequency responses, before and after faulty case. Via this method, the variation between these frequency responses can be represented by a single value on range. The researchers proposed a many of statistical and mathematical methods of indices for FRA application in their literature [28], this for more accuracy achievement in diagnosing the FRA. In this study, the algorithm that proposed by authors in [29, 30], has been used for analysing the responses, which is North China Electric Power Research Institute (NCEPRI) algorithm. The NCEPRI algorithm validate the data matching of FR responses by finding the effective deviation (ED) or assessment factor (E12) between reference frequency responses transfer function $(T F 1 i)$ and compared frequency responses transfer functions (TF2i) using equation (1).

$$
E_{12}=\frac{1}{N} \sum_{i=1}^{N}\left(T F_{1 i}-T F_{2 i}\right)^{2}
$$

Where: $N$ is the number of data matching. Theoretically, all FR measurements of three units as clearly visible in Figure 3, Figure 4 and Figure 5 reveal some important differences between frequency responses, before and after faulty case. As we note in FRA of the SC fault it was caused obvious variations in curved deflection of low frequency region from the beginning. NCEPRI algorithm was utilized for distinguish the similarities and differences between the FR at normal condition and winding SC fault case. Table 2 reveals the assessment factor or ED between the phases frequency responses at SC fault in windings. On the other hand, the table shows the ranges of frequencies definite according to the wave-shape responses.

Table 2. Assessment factor $\left(\mathrm{E}_{12}\right)$ of SC fault frequency responses by using NCEPRI algorithm

\begin{tabular}{cccccccccc}
\hline \multirow{2}{*}{ Frequency range } & \multicolumn{3}{c}{$\mathrm{E}_{12}$ in $\mathrm{dB}$ for $1 \mathrm{HP}$ motor } & \multicolumn{2}{c}{$\mathrm{E}_{12}$ in $\mathrm{dB}$ for $2 \mathrm{HP}$ motor } & \multicolumn{3}{c}{$\mathrm{E}_{12}$ in dB for 3HP motor } \\
& $\mathrm{U}-\mathrm{V}$ & $\mathrm{V}-\mathrm{W}$ & $\mathrm{W}-\mathrm{U}$ & $\mathrm{U}-\mathrm{V}$ & $\mathrm{V}-\mathrm{W}$ & $\mathrm{W}-\mathrm{U}$ & $\mathrm{U}-\mathrm{V}$ & $\mathrm{V}-\mathrm{W}$ & $\mathrm{W}-\mathrm{U}$ \\
\hline $20 \mathrm{~Hz}-2 \mathrm{kHz}$ & 0.7543 & 0.0019 & 0.7500 & 1.3063 & 0.0008 & 1.3202 & 1.0612 & 0.0027 & 1.0801 \\
$2 \mathrm{kHz}-20 \mathrm{kHz}$ & 1.2893 & 0.0011 & 1.2625 & 1.8335 & 0.0017 & 1.8458 & 1.8259 & 0.0034 & 1.8728 \\
$20 \mathrm{kHz}-200 \mathrm{kHz}$ & 1.1434 & 0.0239 & 1.1778 & 2.2173 & 0.0306 & 2.1789 & 1.8926 & 0.0308 & 1.8299 \\
$200 \mathrm{kHz}-2 \mathrm{MHz}$ & 0.1586 & 0.0795 & 0.1436 & 0.2196 & 0.1223 & 0.2789 & 2.2574 & 0.2079 & 2.4358 \\
\hline
\end{tabular}

The different ranges of frequencies are divided according to the wave-shape responses. Clearly of course the response curve shapes will be different for the TPIMs because they are different and have power rating (1, 2 and 3 horse power). It can be seen from Table 2 that the assessment factor (E12) for fault calculated between $\mathrm{U}$ to $\mathrm{V}$ and $\mathrm{W}$ to $\mathrm{U}$ phases at SC fault condition is high for the frequency region $(20 \mathrm{~Hz}-$ $2 \mathrm{kHz}$ ). Therefore, this region is considered as serious failure because of faulty winding case. In the second and third frequency region $(2 \mathrm{kHz}-20 \mathrm{kHz})$ and $(20 \mathrm{kHz}-200 \mathrm{kHz})$ respectively, also the $\mathrm{E} 12$ of $\mathrm{U}$ to $\mathrm{V}$ and $\mathrm{W}$ to $\mathrm{U}$ phases was high it was considered as serious distorted. More clearly, all values are above 1 (E12>1). Meanwhile, E12 of the last region $(200 \mathrm{kHz}-2 \mathrm{MHz})$ for all units is considered as slight distortion region, which calculated between $\mathrm{U}$ to $\mathrm{V}$ and $\mathrm{W}$ to $\mathrm{U}$ phases at $\mathrm{SC}$ fault condition. Moreover, that the assessment factor (E12) for fault is considered as in a normal condition in the $\mathrm{V}$ to $\mathrm{W}$ phases.

\section{CONCLUSION}

Frequency response analysis technique for induction motor short circuit faults detection (A. A. Alawady) 
This paper presents the interpretation of TPIM FRA signature by the variation in the FRA response on internal SC fault on induction motor stator winding. Findings of this paper, it has been proven that the comparison of frequency responses (FR) confirmed that the internal SC fault in TPIM stator winding gives some of variation in the FRA response. And also, from the conclusions of this study, we can diagnose that the defect occurred in one phase only and have no effect on the other phases, through the variation in the FRA response in phases and the absence of any response or variance in other phases when measuring the frequency response. And also, this paper was presented the validation and interpretation for FRA due to internal SC fault case by using NCEPRI algorithm which is considered as one of a certified statistical indicator. The assessment factor (E12) which was calculated by using NCEPRI algorithm shows the highest distortion indicator of frequency regions that has low frequency range. Increases of frequencies lead to reduce the level of distortion. This prove a significant effect of the internal SC fault to low frequency region. Faults effect decreases gradually at the medium frequency region and the effect is relatively insignificant in the high frequency region. The proposed method in this paper had a useful result for detect and diagnosis of stator windings faults of TPIM. The applications of developed method can be used for diagnosis and detection the faults of other machines types.

\section{ACKNOWLEDGEMENTS}

Authors of this paper are grateful to the TNB Research, for the provision of tests equipment, especially the FRANEO 800 device to do the FRA measurements.

\section{REFERENCES}

[1] Akar Mehmet, Ankaya Ilyas C., "Broken rotor bar fault detection in inverter-fed squirrel cage induction motors using stator current analysis and fuzzy logic," Turk J Elec Eng \& Comp Sci, vol. 20, no. 1, pp. 1077-1089, 2012.

[2] Husain Ashfaq, "Three-phase induction motor," in Electric Machines, Dhanpat Rai and Co. (Pvt.) Ltd., 2004.

[3] Bimbhra P. S., "Basic Concepts of Rotating Electrical Machines," in Electrical Machinery, Khanna Publication, 2011.

[4] Aderiano M., Da Silva, "Induction motor fault diagnostic and monitoring methods," Facluty of Electrical and Computer Engineering, Marquette University, pp.1-159, 2006.

[5] Colak, I., R. Bayindir, A. Bektas, I. Sefa, and G. Bal., "Protection of induction motor using PLC," 2007 International Conference on Power Engineering, Energy and Electrical Drives, pp. 96-99. IEEE, 2007.

[6] Qi, Xiang, "Practical Circuit Design to Protect Motor's Phase Failure Operation," 2010 Asia-Pacific Conference on Power Electronics and Design, pp. 104-107. IEEE, 2010.

[7] G. B. Kliman, W. J. Premerlani, R. A. Koegl, and D. Hoeweler, "A new approach to on-line fault detection in ac motors," Proc. IEEE Industry Applications Soc. Annual Meeting Conf., pp. 687-693, 1996.

[8] P. Zhang, Yi Du, T. G. Habetler, Bin Lu, "A Survey of Condition Monitoring and Protection Methods for MediumVoltage Induction Motors," IEEE Trans. Ind. Appl, vol. 47, no. 1, 2011.

[9] Thakur, Alka, Sulochana Wadhwani, and Vandana Sondhiya., "Health monitoring of rotating electrical machine using soft computing techniques: A Review," International Journal of Scientific and Research Publications, vol. 3 , no. 11, pp. 1-3, 2013.

[10] Pezzani C, Donolo P., Bossio G., Donolo M., Guzman A., Zocholl S. E., "Detecting broken rotor bars with zerosetting protection," Industrial \& Commercial Power Systems Technical Conference (I\&CPS), IEEE/IAS 48th., pp. 1-12, 2012.

[11] Kompella, KC Deekshit, Venu Gopala Rao Mannam, and Srinivasa Rao Rayapudi, "DWT based bearing fault detection in induction motor using noise cancellation," Journal of Electrical Systems and Information Technology, vol. 3, no. 3, pp. 411-427, 2016.

[12] W. T. Thomson and M. Fenger, "Current Signature Analysis to Detect Induction Motor Faults", IEEE Industry Applications Magazine, vol. 7, no. 4, pp. 26-34, 2001.

[13] W. T. Thomson, "On-Line MCSA to Diagnose Shorted Turns in Low Voltage Stator Windings of 3-Phase Induction Motors Prior to Failure," Proc. 2001 IEEE IEMDC'01, pp. 1-8, 2001.

[14] Joksimovic, Gojko M., and Jim Penman, "The detection of inter-turn short circuits in the stator windings of operating motors," IEEE Transactions on Industrial electronics, vol. 47, no. 5, pp. 1078-1084, 2000.

[15] A. Stavrou, H. Sedding, and J. Penman, "Current monitoring for detecting inter-turn short circuits in induction motors," IEEE International Electric Machines and Drives Conference. IEMDC'99. Proceedings, pp. 345-347. IEEE, 1999.

[16] J. Penman, H. G. Sedding, B. A. Lloyd, and W. T. Fink, "Detection and location of interturn short circuits in the stator windings of operating motors," IEEE Trans. Energy Convers., vol. 9, no. 4, pp. 652-658, 1994.

[17] H. A. Toliyat and T. A. Lipo, "Transient analysis of cage induction machines under stator, rotor bar and end ring faults," IEEE Trans. Energy Convers., vol. 10, no. 2, pp. 241-247, 1995.

[18] S. Williamson and P. Mirzoian, "Analysis of cage induction motor with stator winding faults," IEEE Trans. Energy Convers., vol. 10, no. 2, pp. 241-247, 1995.

[19] M. Arkan, D. K. Perovic, and P. Unsworth, "Online stator fault diagnosis in induction motors," Proc. Inst. Elect. Eng., Elect. Power Appl., vol. 148, no. 6, pp. 537-547, 2001. 
[20] S. M. A. Cruz and A. J. M. Cardoso, "Diagnosis of stator inter-turn short circuits in DTC induction motor drives," Proc. IEEE Industry Applications Soc. Annual Meeting Conf., pp. 1332-1339, 2003.

[21] S. M. A. Cruz, A. J. M. Cardoso, and H. A. Toliyat, "Diagnosis of stator, rotor, and airgap eccentricity faults in three-phase induction motors based on the multiple reference frames theory," Proc. 38th Industry Applications Annual Meeting Conf., pp. 1340-1346, 2003.

[22] Vilhekar, Tushar Gulabrao, Makarand Sudhakar Ballal, and Bhimrao S. Umre, "Application of Sweep Frequency Response Analysis for the detection of winding faults in induction motor," IECON 2016-42nd Annual Conference of the IEEE Industrial Electronics Society, pp. 1458-1463, IEEE, 2016.

[23] S. Al-Ameri, A. A. Alawady, M. F. M. Yousof, H. Ahmad, Ali. A. Salem, and M. A. Talib, "Frequency response analysis for transformer tap changer damage detection," International Journal of Power Electronics and Drive Systems (IJPEDS), vol. 11, no. 1, pp. 350-358, 2020.

[24] N. F. M. Yasid, A. A. Alawady, M. F. M. Yousof, M. A. Talib and M. S. Kamarudin, "The Effect of short circuit fault in three-phase core-typed transformer," International Journal of Power Electronics and Drive Systems (IJPEDS), vol. 11, vo. 1, pp. 409-416, 2020.

[25] Glowacz, Adam, "Fault diagnosis of single-phase induction motor based on acoustic signals," Mechanical Systems and Signal Processing, vol. 117, pp. 65-80, 2019.

[26] "IEEE Guide for the Application and Interpretation of Frequency Response Analysis for Oil-Immersed Transformers IEEE Power and Energy Society," IEEE Std C57.149-2012, pp. 1-72, 2013.

[27] P. Picher, "Mechanical Condition Assessment of Transformer Windings Using Frequency Response Analysis (FRA)," Cigre, Evaluation, vol. A2. 26, pp. 30-34, 2008.

[28] N. F. M. Yasid, A. A. Alawady, M. F. M. Yousof, S. Al-Ameri and M. S. Kamarudin, "Interpretation of sweep frequency response analysis traces on inter-turn short circuit fault," International Journal of Power Electronics and Drive Systems (IJPEDS), vol. 11, no. 1, pp. 309-316, 2020.

[29] OMICRON, "FRAnalyzer User Manual - SFRA Analyzer for Power Transformer Winding Diagnosis," 2006.

[30] NCEPRI, "Application Guideline for Transformer Winding Distortion Test Technology," 1999.

\section{BIOGRAPHIES OF AUTHORS}

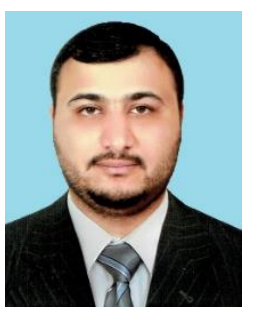

Ahmed Allawy Alawady. He received his bachelor degree (B.Eng.) in Electrical Engineering from University of Kufa, Iraq in 2007. He received master degree (M.Eng.) in Electrical power system from (SHUATS), India in 2012. He is a lecturer at Collage of Technical Engineering, The Islamic University, Iraq since 2007. Currently he is pursuing his Ph.D. Degree in Universiti Tun Hussein Onn Malaysia (UTHM). His research is on motors faults detection using Frequency Response Analysis (FRA) technique.

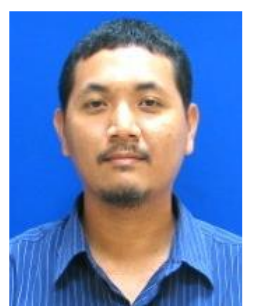

Mohd Fairouz Mohd Yousof. He obtained Dip. Eng, B. Eng and M. Eng from Universiti Teknologi Malaysia. He completed his Ph.D. study in 2015 from The University of Queensland, Australia and currently a lecturer at the Department of Electrical Power Engineering, Universiti Tun Hussein Onn Malaysia (UTHM). He was a visiting researcher for a year with TNB Research in 2018. His main research is condition-based monitoring and assessment of power transformer and rotating machine. He is actively involved with projects from local and international industries.

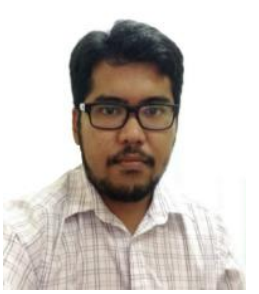

Norhafiz Azis. He received B. Eng degree in Electrical and Electronic Engineering (2007) from Universiti Putra Malaysia and PhD degree in Electrical Power Engineering (2012) from The University of Manchester in UK. Currently, he is an associate professor at the Department of Electrical and Electronic Engineering, Universiti Putra Malaysia, Malaysia. His research interests are in-service ageing of transformer insulation, condition monitoring, asset management, high voltage engineering and alternative insulation materials for high voltage equipment.

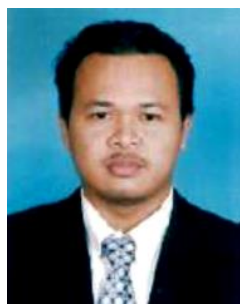

Mohd Aizam Talib. He received his Bachelor in Electrical Engineering from the University of Portsmouth, UK in 1997, Master degree in Electrical Engineering from Universiti Tenaga Nasional (UNITEN), Malaysia in 2001, and Ph.D. degree from Universiti Teknologi Malaysia in 2017. Upon graduation in 1997, he worked with ABB Transmission and Distribution Sdn Bhd as a Design Engineer. Since 1998, he has been employed by TNB Research Sdn Bhd as a Research Engineer and now is a technical expert on transformer. His research interests are in transformer condition monitoring, insulation diagnostic and dielectric measurements. 